\title{
Lacan e a negatividade do desejo
}

\author{
Tiago Ribeiro Nunes* \\ Universidade Federal de Goiás, Curso de Psicologia. Catalão, GO, Brasil
}

\begin{abstract}
Resumo: $O$ presente trabalho pretende demonstrar que, na primeira parte do ensino de Jacques Lacan, a assunção subjetiva do desejo enquanto falta-a-ser representa o ponto de chegada de uma psicanálise. Recorrendo aos textos inaugurais do seu ensino, veremos que é justamente a falta de um saber imanente, capaz de designar o objeto compatível com as suas necessidades, que impõe ao desejo sua negatividade, sintomaticamente expressa na forma do "que queres tu de mim?", com a qual o sujeito pretende reparar a inconsistência do Outro. Tal como propõe o psicanalista francês, uma experiência com a psicanálise levada ao seu limite deveria produzir a assunção pelo sujeito do seu desejo enquanto pura falta-a-ser, em razão da qual se liquidaria o seu endereçamento ao Outro como fundamento último.
\end{abstract}

Palavras-chave: desejo, Lacan, psicanálise.

\section{Introdução}

$\mathrm{Na}$ abertura do seminário dedicado aos Escritos técnicos de Freud, Lacan recorre à figura do mestre zen a fim de exemplificar o que ele designava ser uma forma de ensino cuja instituição implicaria em "uma recusa de todo sistema" (Lacan, 1953-1954/1986, p. 9). Naquele momento preciso, no instante mesmo em que começavam a ser traçadas as coordenadas formais do seu retorno a Freud, o psicanalista francês sublinhava a permanente abertura à revisão que havia caracterizado a posição adotada pelo inventor da psicanálise ao longo de todo o seu empreendimento teórico. Da suspeita pessoal de que em Freud "cada noção possui vida própria" (Lacan, 1953-1954/1986, p. 9), Lacan extrai a seguinte conclusão (absolutamente decisiva para os rumos que seu ensino tomaria no futuro): seria um erro grave, até mesmo um equívoco irremediável, reduzir a experiência freudiana a um certo número de clichês teóricos e clínicos, pois aqueles mesmos conceitos que foram fecundos no momento de seu surgimento acabariam por se transformar, ao longo do tempo, em um amontoado de "palavras gastas" (Lacan, 1953-1954/1986, p. 09). Por esse motivo, o assim designado retorno a Freud, construído com base na leitura atenta dos escritos freudianos, representaria não apenas o esforço empreendido por Lacan a fim de voltar às fontes, mas sobretudo a tentativa de lançar nova luz sobre a invenção freudiana - ainda que para isso fosse necessário, por vezes, tomar Freud pelo avesso (Miller, 1999). A pouca ortodoxia, somada ao desapego em relação às formas já então tradicionais de se ler e aplicar às formulações freudianas, permitiu ao psicanalista francês avançar em seu ensino seguindo, por vezes, mais de um movimento simultaneamente. Assim, por exemplo, ao mesmo tempo em

* Autor correspondente: ribeiro.nunes@gmail.com que se esforçava para restituir à palavra o seu devido valor no interior do campo psicanalítico (consequência maior da formulação de que o inconsciente freudiano opera regido pelas mesmas leis gerais que regem toda linguagem), Lacan formulava também a gênese do $e u$ em sua tópica do imaginário. Ora, fosse unicamente por sua simultaneidade, apesar de possuírem antecedentes diversos e de seguirem diferentes linhas de desenvolvimento teórico, os movimentos a partir dos quais Lacan configura o inconsciente-linguagem e estabelece a gênese imaginária do eu não devem ser considerados enquanto mutuamente exclusivos. Isso na medida em que ambos os movimentos em questão completam-se um no outro: seja sob a forma da oposição (que ajuda a demarcar o campo específico de cada um deles), seja sob a forma da invasão de um sobre o outro (que ratifica o caráter artificial de qualquer separação pretensamente estrita dos campos em questão). Desse modo, se a tese sobre o conhecimento paranoico, enunciada por Lacan em 1932, se completa pela formalização dos mecanismos de formação do eu a partir da imagem especular do outro, a tese lacaniana do inconsciente-linguagem somente pôde ser promovida ao primeiro plano da prática psicanalítica a partir do momento em que foi possível opor, nesse contexto, aquilo que se realiza ao nível da palavra plena (e que abre para o sujeito uma via privilegiada de acesso àquilo que fora recalcado) àquilo que se realiza ao nível imaginário (e que significa o fechamento em relação a qualquer reconhecimento autêntico). Por outro lado, se a estruturação imaginária por meio da qual o $e u$ se constitui encontra-se em estreita dependência do assentimento do Outro para efetivar-se, a identificação simbólica à qual o sujeito encontra-se aderido impõe à metonímia da cadeia significante uma inércia típica do imaginário. Disso resulta que o imaginário e o simbólico se configuram e se definem teoricamente por suas características específicas, mas também por aquilo 
que, consideradas as suas particularidades, faz de cada um dos dois registros, a um só tempo, o contraponto e o complemento necessário do outro. No presente artigo pretendemos demonstrar que, na primeira parte do ensino de Jacques Lacan, a assunção subjetiva do desejo enquanto falta-a-ser representa o ponto de chegada de uma psicanálise levada ao seu limite.

\section{Retornar a Freud}

Caso houvesse sido apenas um vagido, o discurso proferido por Jacques Lacan no Instituto di Psicologia della Universitá di Roma em 26 de setembro de 1953 a fim de introduzir o relatório intitulado Função e campo da fala e da linguagem em psicanálise, teria ainda assim cumprido sua intenção primeira. Isso na medida em que ali se requisita, de modo enfático, a renovação, no âmbito da psicanálise, dos "fundamentos que ela retira da linguagem” (Lacan, 1953/1998, p. 239). Não por acaso, o referido relatório, distribuído por Lacan aos participantes do Congresso de Roma e posteriormente publicado nos seus Escritos, principia por um recurso à etimologia: àquela do termo vagire, surgido para designar "os primeiros balbucios da fala" (Lacan, 1953/1998, p. 239). Trata-se evidentemente de um recurso performativo, pois ao vagire, que designa etimologicamente os primeiros ensaios de fala, Lacan alinha um discurso e um escrito nos quais são lançadas as bases formais do que viria a ser o lacanismo. É bem verdade que o chamado Relatório de Roma ganhou fama e notoriedade por afirmar, rompendo com os standards fixados pelas sociedades psicanalíticas tuteladas pela International Psichoanalytical Association (IPA), que a psicanálise é uma prática de linguagem. Conforme procurou demonstrar, fornecendo em sua comunicação (mas também nos seminários e escritos, especialmente aqueles produzidos durante a década de 1950) todas as provas de que dispunha naquele momento, essa era, rigorosamente falando, a verdadeira novidade daquilo que Freud havia designado sob o título do inconsciente. Alguns anos mais tarde, em um escrito que deve ser considerado como um dos mais representativos desse momento teórico, Lacan afirmaria de modo provocativo que o inconsciente freudiano, diferente de tudo aquilo que o precedeu, "não é o primordial nem o instintivo e, de elementar, conhece apenas os elementos do significante" (Lacan, 1957/1998, p. 526). Lançavam-se, assim, em tom de desafio, os pilares de um ensino que pretendia em seu início estabelecer as vias de retorno à letra freudiana e aos fundamentos da psicanálise. Conjugada a esta intenção primeira e confessa encontrava-se, todavia, outra: permitir que "as pessoas continuassem a [poder] se arriscar a uma psicanálise, a se meter nesse dispositivo que, sem isso, se tornaria um dispositivo morto" (Miller, 2012, p. 24). Para Lacan, nada poderia ser considerado mais estranho à descoberta freudiana do que uma terapêutica protocolar cujos standards operavam basicamente a fim de "refazer o $e u$ do paciente à imagem do $e u$ do analista" (Lacan, 1953/2003, p. 150, grifos do autor). Mas se era isso o que a psicanálise havia se tornado, fazia-se imperativo reconduzi-la de volta ao seu estado primeiro. Reorientar a teoria e a prática da psicanálise em relação a este ponto não seria, entretanto, uma tarefa simples de ser levada a cabo. Afinal, tratava-se de nada menos do que fazer com que toda uma comunidade organizada em torno da psicanálise e dos seus "standards de prática e de formação" (Miller, 2012, p. 24), abrisse mão dos protocolos que garantiam até aquele momento a sua coesão e a sua força institucional. Para que esse projeto fosse executável, porém, seria necessário não apenas demonstrar o quanto a invenção freudiana tinha a ganhar ao apropriar-se dos modelos fornecidos naquele momento pela linguística e pela antropologia estrutural. Sua viabilidade dependia ainda de que se conseguisse levar a comunidade psicanalítica a abandonar uma posição já sedimentada pela ortodoxia que fazia com que, orientando-se prioritariamente em torno de questões relativas às relações de objeto, às fantasias pré-edípicas e à contratransferência, a descoberta freudiana houvesse sido reduzida a uma clínica do prolongamento de formas imaginárias tais como "a pedagogia materna, a ajuda samaritana e a mestria/ dominação dialética" (Lacan, 1953/1998, p. 244). Para efetivar-se, tal correção de perspectiva requeria necessariamente uma alteração substancial das políticas institucionais, bem como dos protocolos de cura e de condução do tratamento. Lacan estava ciente da hostilidade que ele atrairia contra si e das possíveis consequências políticas que poderiam ser desencadeadas em razão do seu gesto. Isso explica que ele tenha ido buscar apoio "junto à instituição psiquiátrica, ao Partido Comunista e à Igreja Católica" (Roudinesco, 2008, p. 279), antes mesmo que o Relatório de Roma houvesse sido publicamente apresentado. Em decorrência das divergências que levaram o grupo psicanalítico francês à ruptura, já era previsto que "a equipe que lograra impor seus estatutos e seu programa [tentasse impedir] de falar em Roma aquele que, juntamente com outros, havia tentado introduzir ali uma concepção diferente" (Lacan, 1953/1998, p. 238). Para tanto, acrescente-se, eles se utilizariam de "todos os meios a seu alcance" (Lacan, 1953/1998, p.238). Em contrapartida, recorrendo à instituição psiquiátrica, ao Partido e à Igreja, Lacan também lançava mão de todos os recursos dos quais ele dispunha pessoalmente para assegurar o seu direito à fala. Fosse outra a situação da psicanálise na França do início dos anos de 1950, é possível que esse projeto de revisão das suas bases conceituais (que implicava repensar a política de formação de analistas em vigência, assim como os princípios norteadores do ato analítico) não houvesse vingado. Mas em decorrência da cisão ocorrida na Sociedade Psicanalítica de Paris (SPP) e da subsequente adesão de Lacan ao grupo fundador da Sociedade Francesa de Psicanálise (no qual ele viria a se afirmar como figura dominante ao longo dos dez anos seguintes, tempo que durou a SFP), as chances de sucesso aumentaram consideravelmente. Em pouco 
tempo, começaram a agrupar-se em torno dele cada vez mais alunos em formação: Lacan começara então a dispor de uma audiência tão necessária ao fortalecimento político da SFP quanto indispensável para o estabelecimento e para a consolidação do seu ensino. A proposta enunciada por ele era clara: renovar na psicanálise seu fundamento linguístico. Em conformidade com ela, o psicanalista francês tratou de opor a fala vazia (aquela que constitui o discurso ordinário) à fala plena (aquela por meio da qual pode haver o reconhecimento legítimo), insistindo em estabelecer a palavra como o elemento que estrutura e fixa os limites do campo psicanalítico. Claro estava que não era dado ao clínico manejar as pulsões ou os afetos (Lacan, 1964/1985). O ofício do psicanalista consistia, ao contrário, em calcular os efeitos que uma determinada interpretação poderia produzir sobre o discurso do sujeito em análise, afinal, conforme propunha Lacan, é nada menos do que "uma pontuação oportuna [aquilo] que dá sentido ao discurso do sujeito" (Lacan, 1953/1998, p. 253). $\mathrm{O}$ ato analítico deveria permitir que o sujeito, após se haver engajado na via do seu discurso, pudesse apropriar-se daquele elemento lacunar à sua história (concebida por Lacan enquanto homóloga a uma cadeia discursiva). Em linhas gerais, aquilo que o psicanalista francês designou a palavra plena seria, pois, a materialização desse instante fecundo no qual o sujeito viria a assumir para si, como efeito do dispositivo analítico, aquela parte do seu discurso que se lhe apresentava sempre de modo falhado. Para o psicanalista francês, era

justamente essa assunção de sua história pelo sujeito, no que ela é constituída pela fala endereçada ao outro, que serve de fundamento ao novo método a que Freud deu o nome de psicanálise. (Lacan, 1953/1998, p. 258)

Sendo assim, retomar o fio cortante da descoberta de Freud exigia, antes de qualquer coisa, adotar a fala como o único meio à disposição do psicanalista em sua prática. Além disso, fazia-se necessário reconhecer o discurso como o seu campo concreto e as suas operações como aquelas da história: história que tem sempre o caráter de uma "ficção encenada" (Lacan, 1963/2005, p. 43). Entretanto, a assunção pelo sujeito desse elemento lacunar não resultaria no advento, para ele, de uma consciência translúcida para a qual o inconsciente deixaria de representar um ponto de opacidade. Conforme expressa o grafo do desejo, elaborado por Lacan no final dos anos de 1950, o sujeito teria de apropriar-se, como efeito de uma psicanálise levada ao seu limite, do significante que designa a falta do Outro, a saber, aquele que materializa de modo radical a inconsistência desse Outro não-todo. Tendo se apropriado do significante da falta do Outro e desinvestido a significação a partir da qual se sustentava o seu desmentido na cadeia discursiva, o sujeito estaria, portanto, liberado para reconhecer o desejo em sua forma pura e desprovida de qualquer conteúdo empírico. Assim, ao contrário da intenção totalizante e integradora que norteia as psicologias clínicas em geral, uma psicanálise não projetaria para o seu final o advento de uma suposta plenitude da consciência.

\section{O inconsciente-linguagem e o corpo vivo}

Ainda no início de seu projeto de empreender o retorno a Freud, o psicanalista francês havia definido o inconsciente freudiano nos seguintes termos: "o inconsciente é o capítulo de minha história que é marcado por um branco ou ocupado por uma mentira: é o capítulo censurado" (Lacan, 1953/1998, p. 260); e ainda, "o inconsciente, a partir de Freud, é uma cadeia de significantes que em algum lugar (numa outra cena, escreve ele) se repete e insiste" (Lacan, 1960/1998, p. 813). Mas se o inconsciente freudiano é uma cadeia significante, ele é também uma escrita que implica necessariamente o corpo vivo, conforme atestam os sintomas neuróticos. Por outro lado, para o Lacan do Relatório de Roma, se o sintoma neurótico era capaz de perturbar o bom funcionamento do corpo vivo, essa era a prova incontestável de que sobre a carne inscreviam-se os efeitos do inconsciente-linguagem: efeitos sempre abertos à revisão/deciframento por meio de uma experiência com a psicanálise . Desse modo, se é verdadeiro que a psicanálise implica "o real do corpo e o imaginário de seu esquema mental", é igualmente verdade que o seu alcance clínico e teórico depende necessariamente de que se note que "as integrações mais ou menos parcelares que parecem produzir sua ordenação funcionam ali, antes de mais nada, como os elementos de uma heráldica, de um brasão do corpo" (Lacan, 1960/1998, p. 818).

Disso resulta que, nesse momento específico da construção lacaniana, o corpo figure prioritariamente enquanto locus paradigmático de inscrição da fraseologia dos sintomas, já que ele está, tal como os "estádios instintuais já estão, ao serem vividos, organizados como subjetividade" (Lacan, 1953/1998, p. 263). Entretanto, a relação entre o corpo vivo e a linguagem revelou-se em Lacan ainda mais complexa do que supõe essa visada primeira. Pois se é no corpo vivo que a linguagem se faz inscrever sob a forma dos sintomas, é também nele que a palavra é objetada: assim, se é verdade que a Cultura impõe ao corpo vivo os seus protocolos, também é verdade que esse mesmo corpo permanece, até certo ponto, como obstáculo irredutível à plena apreensão conceitual. Da operação de inclusão do corpo vivo pela linguagem resulta sempre uma perda, um resto, dirá Lacan (1963/2005). O que se perde na transcrição significante do corpo é, em certo sentido, a totalidade orgânica engendrada pelo instinto. Submetido às leis da linguagem, o corpo vivo será decomposto: da unidade orgânica que havia inicialmente veremos advir uma pluralidade de zonas erógenas autônomas. Dizer que o que se perde no ponto em que o corpo é capturado pela linguagem é a sua unidade significa ainda que não haverá mais para ele qualquer complementaridade entre as necessidades 
(não mais definidas biologicamente) e os objetos disponíveis para a sua satisfação.

Por isso Lacan pôde postular um desejo tão heterogêneo às necessidades do corpo quanto diverso da demanda. Como efeito da submissão do corpo vivo à linguagem, o universo humano se institui em torno de um desejo que se revela ser desejo de reconhecimento. Conceito forjado a partir da leitura de Hegel (feita via Alexander Kojève) e que pode ser lido, no limite, como relativo à mobilização da cadeia simbólica a fim de fazê-la contornar, ainda que sob a forma da fantasia $(\$ \vee a)$, aquele elemento que materializa a sua falta: isso na medida em que a falta que perfura o campo do Outro é precisamente aquela de um saber imanente ao corpo vivo. Por esse motivo, tal como assinala Jacques Allain-Miller, Lacan definirá o desejo como

um desejo evanescente, cujo único objeto e única satisfação é ser reconhecido pelo outro. Sem nenhuma substância, o que o dominaria, o enquadraria, o habitaria, seria o desejo de reconhecimento. (Miller, 1999, p. 40)

Nesses termos, seria bastante justificado pensar que aquela satisfação libidinal que víamos animar o corpo, sob a forma sempre intempestiva do gozo imaginário, encontra-se aqui relativamente obliterada por essa outra modalidade de satisfação que é eminentemente simbólica: aquela advinda do ato de fazer-se reconhecer ao nível do Outro. Esta parece ser, todavia, uma conclusão por demais apressada e, por isso mesmo, incompleta. Isso na medida em que ela, ancorada como está na estrita distinção dos registros imaginário e simbólico, desconsidera as interferências recíprocas de um registro sobre o outro. Tal como encontra-se enunciada, ela se mostra incompatível com a versão acabada do grafo do desejo, elaborado por Lacan ao longo do seu seminário sobre as formações do inconsciente (Lacan, 1957-1958/1999) e retomado no escrito sobre a subversão do sujeito e a dialética do desejo (Lacan, 1960/1998). Nele vemos surgir, enquanto pura intenção, o sujeito barrado que, depois de atravessar o ponto no qual o Outro se encontra situado, retroage na cadeia significante sob a forma do $s(\mathrm{~A})$ (significação que condensa em sua inércia imaginária o sentido que servirá de alicerce para a identificação simbólica) para refletir-se em seguida em I(A). Ao definir o desejo como desejo de reconhecimento, ao afirmá-lo desejo do Outro, Lacan sublinhava o caráter descentrado desse desejo alienado ao Outro e irredutível aos objetos da experiência. Insistindo neste ponto, à certa altura do Relatório de Roma ele dirá:

em parte alguma evidencia-se mais claramente que 0 desejo do homem encontra seu sentido no desejo do outro, não tanto porque o outro detenha as chaves do objeto desejado, mas porque seu primeiro objeto é ser reconhecido pelo outro. (Lacan, 1953/1998, p. 268)
Devem ser ressaltados aqui dois pontos: a) dizer que o outro (sendo ele alteridade imaginária ou alteridade simbólica) não detém as chaves do objeto equivale afirmá-lo enquanto carente de um objeto empírico capaz de positivar a negatividade radical desse desejo em seu estado puro; b) dado o seu caráter negativo, o primeiro objeto do desejo do homem não poderia ser outro senão fazer-se reconhecer pela alteridade e com isso estabilizar-se enquanto positividade provisória.

Não por acaso Lacan se referirá a uma satisfação própria a esse movimento de reconhecimento. Na primeira parte do seminário sobre As formações do inconsciente (Lacan, 1957-1958/1999), tendo isolado a estrutura formal do chiste, Lacan pensará a satisfação proveniente dessa formação do inconsciente enquanto puro fato de linguagem: "una satisfacción de orden semántico" (Miller, 2008, p. 224), aquela que se dá no instante mesmo em que o Outro reconhece e autentica a mensagem. Nessa perspectiva, dado o privilégio atribuído ali ao significante sobre o corpo e sobre os afetos, o ponto de vista econômico sublinhado por Freud em sua análise do Witz parece haver sido deixado em segundo plano. Ao Lacan que conduz o retorno a Freud parecia interessar menos a convulsão que o chiste é capaz de produzir no corpo vivo sob a forma do riso do que destrinchar sua mecânica identificando suas engrenagens estruturais, bem como os efeitos que dela podem advir. Com isso ele salientava que, no caso do animal humano, embora haja um circuito de gozo que obedece à dinâmica dos investimentos imaginários, a verdadeira satisfação seria sempre aquela concernente ao simbólico. A satisfação autêntica (e, por que não dizer, aquela que a prática clínica visa a desencadear) seria produzida, portanto, no momento privilegiado em que uma mensagem nova, heterogênea ao código instituído, vê-se por ele acolhida e "sancionada" (Lacan, 1957-1958/1999, p. 28): "o prazer se consuma para o sujeito" (Lacan, 1957-1958/1999, p. 104) na medida em que a novidade comunicada por ele sob a forma da tirada espirituosa recebe do Outro o seu aval.

\section{Reconhecer o desejo como falta-a-ser}

Todavia, se é possível falar de uma satisfação própria ao campo do Outro, não se deveria perder de vista os efeitos de gozo desencadeados no corpo a partir da conjunção do imaginário com o simbólico. Isso porque o imaginário humano encontra-se sustentado pelo simbólico, e também porque o simbólico se presta à estagnação imaginária, prova disso são o s(A) e o I(A) inscritos no grafo de Lacan. A aderência do simbólico ao imaginário foi designada por Lacan sob a forma de uma significação cristalizada, cuja inércia encontra-se condicionada pela fantasia (situada no grafo como anteparo à inconsistência do Outro). Acrescente-se a isso o fato de que tal significação surge apenas em razão da necessidade interna de equacionar o impasse imposto ao simbólico pelo corpo vivo: heterogêneo à linguagem, ele encarna a própria inconsistência do Outro, impondo assim esse esforço de linguagem 
a partir do qual o significante da falta no Outro, obliterado pela fantasia $(\$ \triangleright$ a), vem condensar-se em seguida sob a forma denegatória do s(A). Assim, muito embora o simbólico e os seus dispositivos tenham continuado a ser prioritários para a compreensão das formações do inconsciente e para a condução de uma psicanálise, deve-se salientar o fato de que toda a maquinaria simbólica revela-se até certo ponto enquanto sintomático esforço de integralização daquilo que não se escreve a não ser sob a forma lacunar do significante que falta ao conjunto da linguagem (aquele que, a rigor, não-cessa-de-não-se-escrever). Referindo-se ao que ele designava ser o dito primeiro, a saber, aquele que "decreta, legifera, sentencia, é oráculo" (Lacan, 1960/1998, p. 822), Lacan acrescentaria: "tomem apenas um significante como insígnia dessa onipotência . . . e vocês terão o traço unário", aquele que, "por preencher a marca invisível que o sujeito recebe do significante, aliena esse sujeito na identificação primeira que forma o ideal do eu" (Lacan, 1960/1998, p. 822). O que se afirma aqui sob a forma do traço unário é, portanto, a aderência do sujeito evanescente a um traço significante ao qual ele se identificará e estará, a partir de então, sob a forma do ideal do eu I(A), alienado. Claro está que não se trata, nesse caso, de uma identificação simétrica àquela que havia se produzido ao longo do estádio do espelho, afinal,

a identificação imaginária é a identificação com a imagem na qual nos parecemos passíveis de ser amados, representando essa imagem "o que gostaríamos de ser", ao passo que a identificação simbólica se efetua em relação ao próprio lugar de onde somos observados, de onde nos olhamos de modo a parecermos mais amáveis a nós mesmos, merecedores de amor. (Zizek, 1992, p. 104)

\section{Apesar disso, entretanto,}

o fato que não deve ser negligenciado nessa distinção é que $i(a)$ já está sempre subordinado ao I(A): é a identificação simbólica (o ponto de onde somos observados) que domina e determina a imagem, a forma imaginária em que parecemos dignos de amor a nós mesmos. (Zizek, 1992, p. 107, grifo do autor)

Dessa forma, postular o desejo enquanto desejo de reconhecimento não resolveria por inteiro a sua problemática, mas a elevaria a um segundo patamar: aquele no qual o desejo em questão, arrancado da inércia que lhe impõe a identificação àquela significação que restitui ao Outro sua completude imaginária, revelará sua absoluta negatividade. Mas o que seria então, em estado puro, esse desejo do qual o sujeito deveria apropriar-se ao final de uma psicanálise? Sabe-se que a desnaturalização das necessidades no humano produz, pela defasagem que existe entre a necessidade e a demanda que surge para lhe representar, um desejo incompatível com os objetos empíricos. Conforme dirá Lacan, "ali onde se trata do desejo, encontramos em sua irredutibilidade à demanda a própria mola do que também impede de reduzi-lo à necessidade" (Lacan, 1960/1998, p. 819). Seria possível dizer que é precisamente em razão da antinomia existente entre o desejo e os objetos empíricos disponíveis que o homem não cessa de remeter-se ao Outro, endereçando-lhe sempre a seguinte pergunta: "che vuoi?" (Lacan, 1960/1998, p. 829). Na falta de um saber imanente capaz de designar o objeto compatível com as suas necessidades, por já não haver mais para ele nem sombra da necessidade em sua realidade pré-linguística, o homem recorre insistentemente ao Outro demandando dele uma resposta a esse respeito. E na medida em que requisita do Outro uma resposta, o homem faz do seu desejo o desejo dessa alteridade a quem ele se endereça: "é muito simplesmente ... como desejo do Outro que o desejo do homem ganha forma" (Lacan, 1960/1998, p. 828) - ainda que essa forma seja aquela interrogativa do "que queres tu de mim?". Por meio dessa pergunta endereçada ao Outro, o sujeito procura certificar-se da existência de um sentido derradeiro naquilo que comparece em sua experiência sempre tão móvel quanto o "anel que vemos desaparecer e reaparecer num jogo de passa-passa” (Lacan, 1953-1954/1986, p. 58): um sentido capaz de condensar o inapreensível objeto supostamente adequado à demanda do Outro. Isso é o que levará Lacan, em seu grafo, a escrever o desejo enquanto uma lacuna, sintoma da hesitação permanentemente expressa sob a forma do "che vuoi?". Mas se o desejo pôde ser assim definido por Lacan foi somente na medida em que "depois de cada basteamento da cadeia significante, que fixa retroativamente seu sentido, resta sempre um certo hiato" (Zizek, 1992, p. 109) entre o que se diz e o que se quer dizer (com aquilo que se diz). Assim, em termos lacanianos, a distância que separa o enunciado (o que se diz) da enunciação (o que se pretende dizer com aquilo que se diz) revela-se exatamente simétrica àquela que separa, respectivamente, a demanda do desejo. Tal como afirma Zizek, se a fantasia ( $\$ \triangleright$ a) é aquilo que comparece como resposta à pergunta, ao "che vuoi?", isso se deve precisamente ao fato de que ela se institui originalmente enquanto "uma tentativa de preencher o vazio criado pela pergunta" (Zizek, 1992, p. 112): estratégia baseada no forçamento de uma significação aparentemente compatível com o enigmático "que quer ele de mim?" (Lacan, 1960/1998, p. 829).

Por outro lado, pode-se dizer que a fantasia, ao mesmo tempo em que se institui enquanto resposta ao "enigma insustentável do desejo do Outro, da falta existente no Outro", "constrói o contexto que nos permite desejar algo" (Zizek, 1992, p. 115-16). Este é o seu paradoxo: "ela é o contexto que coordena nosso desejo, mas é, ao mesmo tempo, uma defesa permanente erigida contra o 'Che vuoi?', um anteparo que esconde o vazio, o abismo do desejo do Outro" (Zizek, 1992, p. 116, grifos do autor), ou, mais precisamente, a inconsistência desse Outro não-todo. Assim, não bastaria apenas afirmar o desejo enquanto desejo de reconhecimento, seria preciso ainda demarcar a antinomia existente entre aquele reconhecimento ancorado na lógica da fantasia e aquele que se encontra para além dela: fazer a transição de uma dinâmica do reconhecimento centrada no objeto evanescente e nos seus sucessivos deslocamentos, 
para aquela na qual o desejo se faria reconhecer como pura forma, desprovida de conteúdo. Disso resulta uma concepção bastante original acerca do final de análise: o instante derradeiro de uma psicanálise estaria marcado pela liquidação da pergunta nesse momento privilegiado no qual o analisando simplesmente "aceita sua existência como não-justificada pelo grande Outro" (Zizek, 1992, p. 111). No contexto teórico específico dos seminários e escritos produzidos ao longo dos anos de 1950, uma experiência com a psicanálise levada ao seu limite deveria produzir a passagem da lógica imaginária (na qual o sujeito, por meio de sua constitutiva identificação ao outro imaginário, encontra-se alienado na significação que desmente a inconsistência do Outro) àquela simbólica (produto do reconhecimento da inconsistência do Outro e da assunção pelo sujeito do desejo como pura falta-a-ser). A assunção pelo sujeito do seu desejo enquanto falta-a-ser desprovida de qualquer conteúdo empírico implicaria, por conseguinte, a liquidação de seu endereçamento ao Outro sob a forma do "che vuoi?". Em que outros termos se poderia definir de modo mais preciso a ocorrência da eliminação da pergunta e da correlativa assunção pelo sujeito da sua falta-a-ser senão como aquele momento em que

o sujeito diz "Não!" a esse brincar-de-passar-anel da intersubjetividade, onde o desejo só se faz reconhecer por um instante para se perder num querer que é querer do outro. Pacientemente ele subtrai sua vida precária das agregações docilizantes do Eros do símbolo, para afirmá-la enfim numa maldição sem palavras. (Lacan, 1953/1998, p. 321)
Desse momento em diante, menos do que fazer-se reconhecer enquanto equivalente do inapreensível objeto que falta à totalidade do Outro, importaria afirmar-se na qualidade daquilo que Lacan designa paradoxalmente como uma maldição sem palavras. Por meio de tal afirmação veríamos concretizar-se a escrita "no interior do saber objetivo, [d]essa negação que apareceu inicialmente a Lacan como falta-a-ser do sujeito" (Safatle, 2005, p. 144). O reconhecimento do "desejo como falta-a-ser que se manifesta como pura negatividade desprovida de objeto" (Safatle, 2005, p. 144) compareceria, pois, enquanto ponto derradeiro a ser alcançado pela dialética do reconhecimento que se realiza ao longo de uma psicanálise. A despedida da esperança de fazer-se reconhecer como o equivalente daquela significação que restituiria ao Outro sua consistência implicaria uma dupla modificação: a primeira relativa à miragem imaginária - (aquela condensada no ideal do eu e que encontra-se sustentada por s(A)) -, que deve necessariamente perder consistência em razão do atravessamento da fantasia que serve de anteparo ao significante da falta no Outro; a segunda concernente à invenção de uma mensagem inaudita, por meio da qual se inscreveria, na carne mesma do Outro, o desejo em sua negatividade absoluta. Essa seria, portanto, nos termos propostos por Lacan até o início dos anos de 1960, a condição propriamente dita de toda liberdade que poderia advir a um sujeito singular como efeito de uma psicanálise levada ao seu limite: ser capaz de sustentar sua renúncia "ao desejo do outro" (Lacan, 1953/1998, p. 321) e aos seus avatares imaginários, impondo-se ao universo discursivo pela violência de uma palavra inesperada - aquela que condensaria em um significante que ainda não se ouviu soar a inconsistência do Outro.

\section{Lacan and the negativity of the desire}

Abstract: This paper intends to demonstrate that, on the first part of Jacques Lacan's teaching, the appropriation of the desire as lack-of-being represents the aim of a psychoanalytical treatment. Referring to his very first texts and seminars, we will see that the lack of an immanent knowledge, capable of designating the object compatible with its necessities, which imposes to desire its negativity, symptomatically expressed on the form of the "che vuoi?", with which the subject intends to mend the Other's inconsistence. As proposes the French psychoanalyst, an experience with the psychoanalysis taken to its limits should produce the subject appropriation of the desire as pure lack-of-being, because of which it would liquidate its addressing to the Other as ultimate foundation.

Keywords: desire, Lacan, psychoanalysis.

\section{Lacan y la negatividad del deseo}

Resumen: El presente trabajo pretende demonstrar que, en la primera parte de la enseñanza de Jacques Lacan, la asunción subjetiva del deseo como falta-a-ser representa el punto de llegada de un psicoanálisis. Recurriendo a sus textos inaugurales de enseñanza, veremos que es justamente la falta de un saber inmanente capaz de designar el objeto compatible con sus necesidades lo que impone al deseo su negatividad. Negatividad sintomáticamente expresa en la forma del "¿qué quieres de mí?", con la cual el sujeto pretende reparar la inconsistencia del Otro. Como propone el psicoanalista francés, una experiencia con el psicoanálisis en su límite debería producir la asunción por el sujeto de su deseo como pura falta-a-ser, en razón de la cual se cerraría su enderezamiento al Otro como fundamento último.

Palabras clave: deseo, Lacan, psicoanálisis. 


\section{Lacan et la négativité du désir}

Resumé: Cet article vise à démontrer que, dans la première partie de l'enseignement de Jacques Lacan, l'appropriation subjetive du désir comme une manque-a-étre représente le point d'arrivée d'une psychanalyse. En utilisant ses premiers textes d'enseignement, nous voyons que c'est précisément l'absence d'un savoir immanent, capable de désigner l'objet compatible avec sa necessité, qui impose au désir sa négativité. Négativité symptomatique exprimé sous la forme de "Que voulez-vous de moi?», avec laquelle le sujet veut réparer l'inconsistance de l'autre. Telle que proposée par le psychanalyste français, une expérience avec la psychanalyse devrait produire l'assomption par le sujet de votre désir comme pur manque-à-être, en raison duquel résoudrait son adressage à l'autre comme fondement ultime.

Mots-clés: desire, Lacan, psichanalyse.

\section{Referências}

Lacan, J. (1985). O seminário: livro 11: os quatro conceitos fundamentais da psicanálise (M. D. Magno, trad.). Rio de Janeiro, RJ: Jorge Zahar. (Trabalho original publicado em 1964)

Lacan, J. (1986). O seminário: livro 1: os escritos técnicos de Freud (Texto estabelecido por Jacques-Alain Miller, B. Milan, trad.). Rio de Janeiro, RJ: Jorge Zahar. (Trabalho original publicado em 1953-1954)

Lacan, J. (1998). Função e campo da fala e da linguagem em psicanálise. In J. Lacan, Escritos (pp. 238-324). Rio de Janeiro, RJ: Jorge Zahar. (Trabalho original publicado em 1953)

Lacan, J. (1998). A instância da letra no inconsciente. In J. Lacan, Escritos (pp. 496-533). Rio de Janeiro, RJ: Jorge Zahar. (Trabalho original publicado em 1957)

Lacan, J. (1998). Subversão do sujeito e dialética do desejo no inconsciente freudiano. In J. Lacan, Escritos (pp. 807842). Rio de Janeiro, RJ: Jorge Zahar. (Trabalho original publicado em 1960)

Lacan, J. (1999).O seminário: livro 5: as formações do inconsciente. Rio de Janeiro, RJ: Jorge Zahar. (Trabalho original publicado em1957-58)

Lacan, J. (2003). Discurso de Roma. In J. Lacan, Outros escritos (pp. 139-171). Rio de Janeiro, RJ: Jorge Zahar. (Trabalho original publicado em 1953)
Lacan, J. (2005). O seminário: livro 10: a angústia. Rio de Janeiro, RJ: Jorge Zahar. (Trabalho original publicado em 1963)

Miller, J-A. (1999). O avesso de Freud. In J-A Miller, Lacan elucidado: palestras no Brasil (pp. 389-407). Rio de Janeiro, RJ: Jorge Zahar.

Miller, J.-A. (2008). La experiencia de lo real em la cura psicoanalitica. Buenos Aires, Argentina: Paidós.

Miller, J-A. Entrevista sobre "O Seminário" com François Ansermet. Recuperado de http://www.opcaolacaniana. com.br/texto2.html

Roudinesco, E. (2008). Jaques Lacan: esboço de uma vida, história de um sistema de pensamento. São Paulo, SP: Companhia das Letras.

Safatle, V. (2005). A paixão do negativo: Lacan e a dialética. São Paulo, SP: Editora da Unesp.

Zizek, S. (1992). Eles não sabem o que fazem: o sublime objeto da ideologia. Rio de Janeiro, RJ: Jorge Zahar. 